\title{
Influência do Aporte Térmico sobre as Características e Propriedades de Cordões de Solda dos Aços AISI 316 e AISI 316L
}

Rafaela dos Santos Silva ${ }^{1}$ (D) b Rudineli Demarque ${ }^{2}$, Ellem Patrícia dos Santos ${ }^{1}$, José Adilson de Castro ${ }^{1}$

${ }^{1}$ Universidade Federal Fluminense - UFF, Departamento de Engenharia Metalúrgica, Volta Redonda, RJ, Brasil.

${ }^{2}$ Universidade Federal do Rio de Janeiro - UFRJ, Departamento de Engenharia Mecânica, Macaé, RJ, Brasil.

Como citar: Silva RS, Demarque R, Santos EP, Castro JA. Influência do Aporte Térmico sobre as Características e Propriedades de Cordões de Solda dos Aços AISI 316 e AISI 316L. Soldagem \& Inspeção. 2020;25:e2504. https://doi.org/10.1590/0104-9224/SI25.04

\begin{abstract}
Resumo: Aços AISI 316 e AISI 316L possuem ampla aplicação industrial, por isso a importância de avaliar a soldabilidade dessas ligas. Neste estudo, foi feita análise comparativa entre as amostras de ambos os aços soldados com aportes de 0,5, 1,5 e 2,5 kJ/mm utilizando processo TIG autógeno. Foi analisada a variação do aporte térmico sobre a morfologia do cordão de solda, o espaçamento entre ferritas $\delta$, a fração volumétrica de ferrita $\delta$ e a microdureza na zona fundida. Os resultados mostraram que as dimensões do metal de solda, o espaçamento entre as ferritas e a fração volumétrica de ferrita $\delta$ tornam-se maiores com o aumento do aporte. As amostras soldadas do aço AISI 316L apresentaram maior espaçamento entre ferritas $\delta$ e maiores frações de ferrita $\delta$ que o aço AISI 316. Quanto à microdureza, o estudo mostrou que quanto mais próximo do centro da zona fundida, maior é o valor de microdureza, sendo a microdureza do aço AISI 316 maior que a do aço AISI 316L. Através de modelagem computacional foi possível avaliar a distribuição de temperatura ao longo das chapas soldadas e comparar o ciclo térmico obtido por simulação com o ciclo calculado experimentalmente para o aporte de 0,5 kJ/mm.
\end{abstract}

Palavras-chave: Aços inoxidáveis austeníticos; Soldabilidade; Processo TIG Autógeno; Modelagem computacional.

\section{Influence of Heat Input on the Characteristics and Properties of AISI 316 and AISI 316L Steels Weld Beads}

\begin{abstract}
AISI 316 and AISI 316L steels have wide industrial application, so the importance of evaluating the weldability of these alloys. In this study, comparative analysis was made between the samples of both welded steels with heat inputs of $0.5,1.5$ and $2.5 \mathrm{~kJ} / \mathrm{mm}$ using autogenous TIG process. The variation of heat input on weld bead morphology, the spacing between $\delta$ ferrite bands, the volumetric fraction of ferrite $\delta$ and the microhardness in the molted zone were analyzed. The results showed that the dimensions of the welding metal, the spacing between ferrite bands and the volumetric fraction of ferrite $\delta$ become larger with the increase of the heat input. The welded samples of AISI 316L steel presented larger ferrite band spacing and larger $\delta$ ferrite fractions than AISI 316 steel. As for microhardness, the study showed that the closer to the center of the molted zone, the greater the microhardness value and the hardness of AISI 316 steel higher than that of AISI 316L steel. Through computational modeling it was possible to evaluate the temperature distribution along the welded plates and compare the thermal cycle obtained by simulation with the experimentally calculated cycle for the input of $0.5 \mathrm{~kJ} / \mathrm{mm}$.
\end{abstract}

Key-words: Austenitic stainless steels; Weldability; Autogenous TIG Process; Computational modeling.

\section{Introdução}

Dentre os aços inoxidáveis, o aço inoxidável austenítico é o que apresenta maior gama de utilização, já que possui boa tenacidade e resistência mecânica em temperaturas elevadas e pode ser empregado em diversos meios corrosivos, tanto em baixas como em alta temperatura, além de possuir boa soldabilidade, segundo McGuire [1]. Porém, devido às transformações que ocorrem na microestrutura quando expostos a altas temperaturas, as propriedades dos aços inoxidáveis austeníticos podem ser facilmente degradadas em operações de soldagem, acarretando em falhas no desempenho do material. Para evitar que isso ocorra, é necessária atenção especial aos parâmetros de soldagem, como corrente, gás de proteção e o aporte térmico. Costanza et al. [2] estudaram a soldabilidade de aços inoxidáveis austeníticos através de soldagem TIG e MIG utilizando diferentes gases de proteção, chegando a conclusão que o aço AISI 316 possui boa soldabilidade mesmo soldado com diferentes composições de gás de proteção. Balram et al. [3] analisaram a distribuição de temperatura e tensões residuais 
nas soldagens TIG e TIG pulsada do aço AISI 316, sendo observadas maiores tensões residuais na soldagem TIG devido ao fornecimento contínuo de calor ao metal base. Samanta et al. [4] estudaram a influência da adição de terras raras no cordão de solda do aço AISI $316 \mathrm{~L}$ soldado por processo TIG, sendo afirmado que a adição de terras raras promove melhor resistência à oxidação do cordão. Almeida et al. [5] analisaram, através de simulação numérica, a solda de topo de chapas finas de AISI 316L obtidas por processo TIG, no qual os resultados numéricos referentes às tensões residuais se encontraram de acordo com os resultados experimentais, o que demonstra a adequação do método dos elementos finitos.

Observa-se que o estudo da soldabilidade dos aços inoxidáveis AISI 316 e AISI 316L com foco nas alterações das propriedades de acordo com as condições de soldagem tem sido alvo de pesquisa nos últimos anos. Entretanto, uma investigação comparativa da soldabilidade de ambos os aços utilizando resultados experimentais e simulação numérica não foi relatada. Sendo assim, o presente trabalho tem como objetivo comparar a soldabilidade dos aços AISI 316 e AISI $316 \mathrm{~L}$ soldados pelo processo TIG autógeno utilizando três diferentes aportes térmicos através da análise das regiões soldadas. Além disso, com base no modelo proposto do Goldak et al. [6] e nos estudos realizados por Xavier [7] e Ronda e Olivier [8] - que estudaram um modelo termo-mecânico-metalúrgico (TMM) no qual o estado do material pode ser definido por quatro variáveis essenciais: tensão, taxa de deformação, fração de fases e temperatura - simular através de modelagem computacional os efeitos da variação do aporte térmico de soldagem sobre a distribuição de temperatura nas amostras soldadas de AISI 316 e AISI 316L e comparar os ciclos térmicos de soldagem obtidos por simulação com os ciclos calculados experimentalmente de ambas as amostras.

\section{Materiais e Métodos}

Foram utilizadas seis chapas de aço inoxidável austenítico laminadas a quente, sendo três de AISI 316 e três de AISI 316L, ambas com as dimensões apresentadas na Figura 1. As composições químicas fornecidas pelo fabricante e propriedades físico-químicas, obtidas no estudo realizado por Santos [9], de ambos os materiais se encontram nas Tabelas 1 e 2.

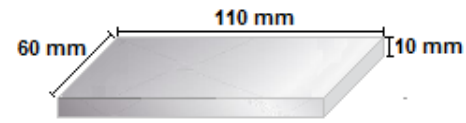

Figura 1. Dimensões das chapas dos aços AISI 316 e AISI 316L.

Tabela 1. Composição química dos aços AISI 316 e AISI 316L.

\begin{tabular}{ccccccccccc}
\hline Material & $\mathrm{C}[\%]$ & $\mathrm{Mn}[\%]$ & $\mathrm{Si}[\%]$ & $\mathrm{P}[\%]$ & $\mathrm{S}[\%]$ & $\mathrm{Cr}[\%]$ & $\mathrm{Ni}[\%]$ & $\mathrm{Mo}[\%]$ & $\mathrm{Cu}[\%]$ & $\mathrm{N}[\%]$ \\
AISI 316 & 0,081 & 1,7 & 0,4 & 0,025 & 0,012 & 18,66 & 11,00 & 2,6 & 0,08 & 0,07 \\
AISI 316L & 0,021 & 1,33 & 0,420 & 0,034 & 0,001 & 17,08 & 10,02 & 2,026 & 0,10 & 0,05 \\
\hline
\end{tabular}

Tabela 2. Propriedades físico-químicas dos aços estudados em função da temperatura [9].

\begin{tabular}{ccccc}
\hline Aço & Densidade $\left(\mathbf{g} / \mathbf{c m}^{3}\right)$ & $\begin{array}{c}\text { Condutividade Térmica } \\
(\mathbf{k J} / \mathbf{m K})\end{array}$ & $\begin{array}{c}\text { Calor específico } \\
(\mathrm{J} / \mathbf{k g K})\end{array}$ & $\begin{array}{c}\text { Coef. de Expansão Térmica } \\
(\mathbf{m} / \mathbf{K})\end{array}$ \\
AISI 316 & & $25,6+0,008 \mathrm{~T}$ & $493+0,12 \mathrm{~T}$ & $0,024 /(\mathrm{T}-25)$ \\
AISI 316L & 7,90 & $46,4+0,0145 \mathrm{~T}$ & $475+0,15 \mathrm{~T}$ & $0,018 /(\mathrm{T}-25)$ \\
\hline
\end{tabular}

Cada uma das três chapas foi soldada em um único passe por processo TIG (Tungsten Inert Gas) autógeno através de um equipamento sinérgico modelo MIG PULSE 4001 DP - CASTOLIN EUTECTIC, utilizando eletrodo de tungstênio de 1/8" e gás de proteção composto de $98 \%$ de argônio e $2 \%$ de oxigênio com vazão de $17 \mathrm{~L} / \mathrm{min}$. Durante o processo de soldagem, foram coletados dados de temperatura, corrente e tensão. Os dados de corrente e tensão foram captados por meio de um sensor de corrente elétrica por efeito Hall Realimentado (SECOHR 250TCS-15), conectado diretamente ao cabo que transfere corrente à tocha. Para a aquisição dos dados de temperatura foram soldados três termopares tipo K na parte inferior de cada uma das chapas, na região correspondente ao centro do cordão de solda. A distância entre cada termopar foi de $25 \mathrm{~mm}$. Os termopares foram soldados a $5 \mathrm{~mm}$ de altura (hf) da chapa, sendo que cada chapa possui $10 \mathrm{~mm}$ de espessura (hc), como ilustra a Figura 2. Através do registro da variação de temperatura durante o processo de soldagem, foi possível a obtenção de gráficos do ciclo térmico de soldagem para cada aporte de ambos os aços, dados que foram usados para comparação com os ciclos térmicos obtidos por simulação. 


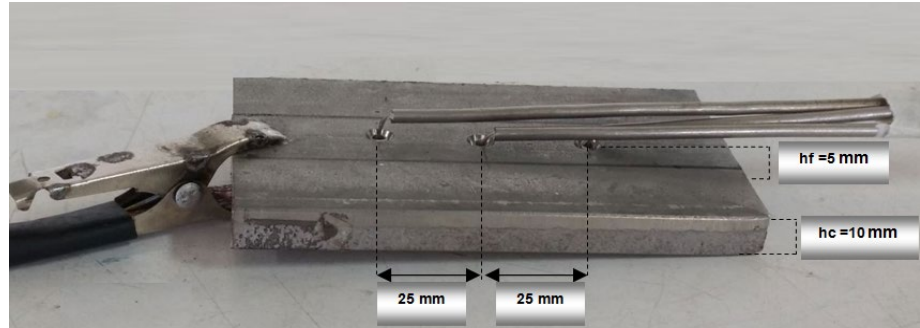

Figura 2. Localização dos termopares nos corpos de prova.

Para o controle da velocidade da tocha durante a soldagem, foi utilizado um inversor de frequência, sendo que a frequência definida no inversor é o que permite calcular a velocidade de soldagem. A Tabela 3 mostra os parâmetros utilizados na soldagem de cada uma das amostras. $\mathrm{O}$ cálculo do aporte térmico foi feito de acordo com a Equação 1, sendo adotado $80 \%$ de eficiência, ou seja, fator de rendimento $\eta$ igual a 0,8 para o processo TIG autógeno [10]. Para facilitar o registro dos dados, as amostras do aço AISI 316 soldadas com os aportes de 0,5, 1,5 e 2,5 kJ/mm foram nomeadas como 5, 15 e 25, respectivamente, enquanto as amostras do aço AISI $316 \mathrm{~L}$ foram nomeadas como $5 \mathrm{~L}, 15 \mathrm{~L}$ e $25 \mathrm{~L}$.

Tabela 3. Parâmetros do processo utilizado para soldar as amostras de AISI 316 e AISI 316L.

\begin{tabular}{ccccccc}
\hline Amostra & $\mathbf{5}$ & $\mathbf{1 5}$ & $\mathbf{2 5}$ & $\mathbf{5 L}$ & $\mathbf{1 5 L}$ & $\mathbf{2 5 L}$ \\
Corrente $(\mathrm{A})$ & 306 & 306 & 306 & 306 & 306 & 306 \\
Tensão $(\mathrm{V})$ & 16,3 & 15,3 & 15,5 & 15,5 & 14,9 & 14,6 \\
Velocidade $(\mathrm{mm} / \mathrm{s})$ & 7,98 & 2,49 & 1,51 & 7,58 & 2,43 & 1,42 \\
Aporte Térmico $(\mathrm{kJ} / \mathrm{mm})^{*}$ & 0,5 & 1,5 & 2,5 & 0,5 & 1,5 & 2,5 \\
\hline
\end{tabular}

*Nota: Valores aproximados do aporte térmico.

AporteTérmico $=\frac{\text { TensãoxCorrentex } \eta}{1000 x \text { VelocidadedeSoldagem }}$

\subsection{Caracterização microestrutural}

Para fins comparativos, foi cortada e embutida uma amostra como recebida (CR) de ambos os aços. As amostras soldadas foram cortadas em partes menores para facilitar o preparo. Todas as amostras foram lixadas em lixadeira manual utilizando lixas de carbeto de silício na granulometria de 220 a 4000 mesh. Em seguida, as amostras foram polidas mecanicamente utilizando como abrasivo solução de alumina de $1 \mu \mathrm{m}$ e 0,05 $\mu \mathrm{m}$ e, finalmente, foram atacadas por imersão com solução de Água Régia, composta de $30 \mathrm{ml}$ de ácido clorídrico $37 \%$ e $10 \mathrm{ml}$ de ácido nítrico.

Para as amostras CR foi calculado o tamanho médio dos grãos de acordo com o método dos interceptos lineares de Heyn, seguindo a norma ASTM E112[11]. Para isso, foi feita a medição do número de interceptos no comprimento de 1 mm nos sentidos vertical e horizontal em três áreas distintas. As amostras soldadas e as amostras CR foram analisadas por microscopia óptica (MO). Nas amostras soldadas foi feita quantificação de ferrita $\delta$ em cinco micrografias de cada amostra, objetivando obter a quantificação média. Também nas amostras soldadas, foi feita medição do espaçamento entre ferritas $\delta$ residuais presentes entre as dendritas de austenita da zona fundida (ZF). Foram utilizadas cinco micrografias, onde se mediu o espaçamento entre ferritas $\delta$ em dez pontos diferentes, resultando em cinquenta medições por amostra. A quantificação e o espaçamento entre ferritas $\delta$ foram feitos através do software ImageJ.

\subsection{Análise macrográfica e microdureza vickers}

As amostras soldadas foram submetidas à análise macrográfica, sendo analisada a morfologia do cordão de solda. As medidas de largura e profundidade de penetração da solda foram feitas utilizando um perfilômetro, já a área do MS foi calculada através do método de inserção de pontos nas macrografias das amostras utilizando o software GeoGebra. As macrografias para o cálculo da área foram obtidas por meio de um estereomicroscópio utilizando aumento de 20X.

Em todas as amostras, CR e soldadas, foi feito ensaio de microdureza Vickers utilizando carga de $300 \mathrm{gF}$ por $20 \mathrm{~s}$. Para fins de comparação, foi feita ensaio de microdureza em ambas as amostras CR, sendo feitos sete pontos de microdureza a fim de se obter a dureza média do material. Para as amostras soldadas, foi feito um perfil de microdureza, ou seja, mediu-se a microdureza em dez pontos em linha, sendo realizada uma indentação por ponto, como mostra a Figura 3. 0 ponto 1 foi medido no metal base $(\mathrm{MB})$, o ponto 2 na zona termicamente afetada (ZTA), o ponto 3 na zona de ligação entre ZTA e ZF e os demais pontos foram medidos na ZF, com o objetivo de mostrar as variações que ocorrem na microdureza ao longo de uma amostra soldada. As medições foram feitas a 0,5 mm de distância da superfície, com distância entre cada indentação de 0,5 mm. 


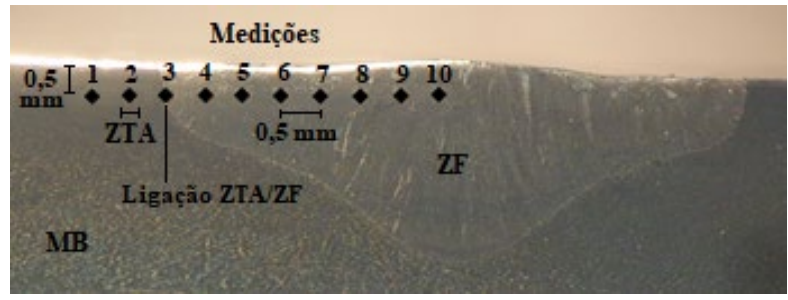

Figura 3. Esquema de medição da microdureza.

\subsection{Modelagem computacional}

Como a soldagem é um processo complexo que envolve altos gradientes de temperatura, dilatação e contração térmica e transformações de fase, foi utilizado o modelo analítico proposto por Goldak et al. [6], que consiste em um modelo volumétrico de distribuição de calor no qual o fluxo de calor é distribuído em uma geometria tridimensional, considerando os efeitos na direção dos três eixos. Este modelo é conhecido como distribuição em duplo elipsoide e é constituído de um volume composto por duas semi-elipses, sendo que uma representa a metade frontal a fonte de calor e a outra representa a metade traseira a fonte. Assim, o modelo de Goldak et al. [6], esquematizado na Figura 4, permite simular a evolução térmica em processos de soldagem de baixa a alta capacidade de penetração, inclusive com material de adição.

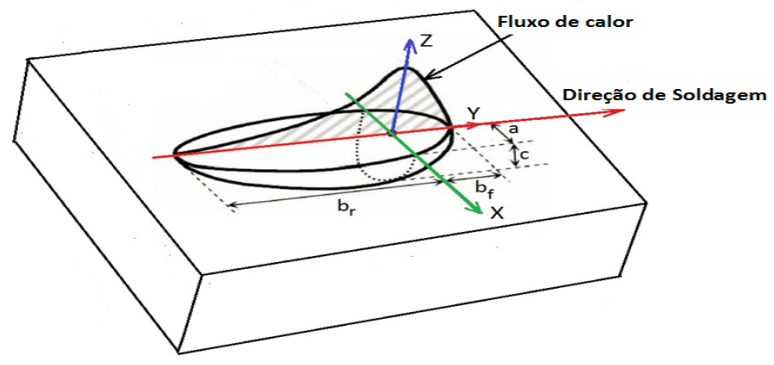

Figura 4. Modelo da fonte de calor duplo-elipsóide. Adaptado de Goldak e Akhlaghi [12].

No processo de modelagem computacional são considerados os fenômenos de transferência de calor (radiação, convecção e condução) juntamente aos fenômenos de transferência de massa (aquecimento, fusão, resfriamento e solidificação). Para modelar o processo de soldagem e fazer a previsão de temperatura nas chapas, foram considerados os mesmos parâmetros do processo experimental. Além disso, durante a elaboração do modelo algumas considerações foram feitas a fim de tornar viável a simulação computacional: velocidade de soldagem constante; perda de calor na superfície da chapa ocorre por convecção e radiação; deposição de somente um cordão de solda; distância constante entre eletrodo e chapa; composição química do metal de base constante. O modelo numérico de previsão de temperatura consiste na resolução da equação diferencial da conservação de energia, Equação 2, aplicada sobre o volume da chapa como domínio de estudo, sendo a temperatura T a variável dependente. As propriedades físico-químicas utilizadas se encontram na Tabela 2.

$\frac{\partial}{\partial t}\left(\rho c_{p} T\right)+\operatorname{div}\left[\rho c_{p}(\vec{u}) T\right]=\operatorname{div}[k[(\operatorname{grad}(T))]]+S$

Sendo:

$\rho:$ Densidade do aço

Cp: Calor específico

k: Condutividade térmica

$\vec{u}$ : Vetor velocidade

T: Campo de temperatura

S: Termo fonte, que corresponde a todas as fontes de entrada ou perda de calor no processo (calor adicionado na soldagem, transformação de fase, fusão e solidificação)

Para resolução da Equação 2 foram consideradas as seguintes condições térmicas de contorno:

a) Como dito anteriormente, no processo de soldagem a perda de calor na superfície da chapa ocorre por convecção e radiação. Logo, utiliza-se a Equação 3 que considera os dois efeitos.

b) Foi utilizado o modelo duplo-elipsóide para modelar a entrada de energia (calor) no processo de soldagem por meio das Equações 2 e 3. Os parâmetros de geometria da distribuição e frações de calor adicionadas à frente e atrás da fonte de energia foram obtidos por meio de ajuste com resultados experimentais de ciclos térmicos captados durante a soldagem. 
$q=q_{c}+q_{r}=h\left(T-T_{0}\right)+\varepsilon \sigma\left(T^{4}+T_{0}^{4}\right)$

Sendo:

$\mathrm{T}_{0}$ (temperatura inicial) $=$ considerada como $25^{\circ} \mathrm{C}$ em todas as faces

$\varepsilon$ (emissividade) $=0,682$

$\sigma$ (constante de Stefan-Boltzman) $=5,67 \times 10^{-8} \mathrm{~W} /\left(\mathrm{m}^{2} \mathrm{~K}^{4}\right)$

$\mathrm{h}$ (coeficiente de convecção) $=15 \mathrm{~W} /\left(\mathrm{m}^{2} \mathrm{~K}\right)$

Os valores da emissividade e coeficiente de convecção foram previamente obtidos no estudo realizado por Santos [9], por meio de ensaio de dilatometria e TGA. A solução para a Equação 2 pode ser obtida por meio da aplicação da técnica de volumes finitos em coordenadas generalizadas. Após integração no tempo e no espaço e arranjos algébricos tem-se formulada a equação da conservação de energia discretizada, Equação 4.

$a_{p} T_{p}=a_{E} T_{E}+a_{w} T_{w}+a_{N} T_{N}+a_{s} T_{s}+a_{T} T_{T}+a_{B} T_{B}+b$

A solução da Equação 4 é então obtida utilizando o método linha por linha descrito por Patankar [13] para o algoritmo tri-diagonal, sendo que os termos desta equação representam os fluxos de energia transportada e seus coeficientes podem ser obtidos através do esquema denominado "power law".

\section{Resultados e Discussão}

\subsection{Análise das amostras como recebidas}

A Figura 5 mostra a microestrutura dos aços AISI 316 e AISI 316L, respectivamente. Observa-se a presença de grãos poligonais austeníticos, como observado em estudos anteriores por Tavares et al. [14] e Demarque et al. [15], além da presença de maclas de recozimento, que se formaram devido ao processo de laminação a quente das amostras CR.
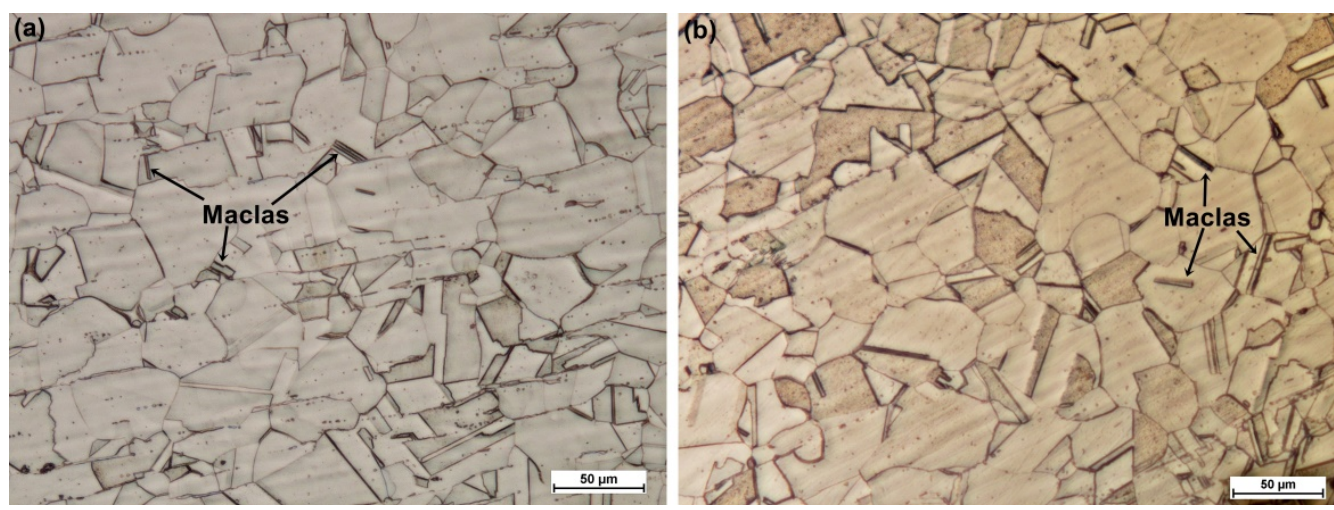

Figura 5. Microestrutura dos aços (a) AISI 316 e (b) AISI 316L. Ataque: Água Régia. Aumento: 200X.

O tamanho médio dos grãos foi de $43 \pm 3 \mu \mathrm{m}$ para a amostra AISI 316 e $31 \pm 2 \mu \mathrm{m}$ para a amostra $316 \mathrm{~L}$. O resultado do tamanho de grão ASTM foi 6 para o aço AISI 316 e 7 para o aço AISI 316L. O ensaio de microdureza resultou em $176 \pm 0,29$ HV para o AISI 316 e $169 \pm$ 0,50 HV para o AISI 316L. O AISI 316 possuir maior microdureza que o AISI 316L já era esperado, pois o aço AISI 316L além de possuir menor teor de carbono, também possui menor teor de elementos de liga, o que faz com seja sua microdureza seja menor.

\subsection{Dimensionamento do metal de solda}

Os valores médios de largura e penetração e os resultados da área do MS para cada amostra soldada se encontram na Tabela 4. Percebe-se que, assim como nos estudos de Souza et al. [16] e Royse [17], as dimensões do MS aumentam à medida que se aumenta o aporte térmico. Isso ocorre, pois quanto maior o aporte, maior a quantidade de energia transferida para a peça, implicando em uma maior poça de fusão. A Figura 6 mostra os gráficos comparativos das dimensões das amostras soldadas de AISI 316 e AISI 316L. As amostras soldadas com maior aporte, 25 e 25L, apresentaram valores altos de dimensionamento devido ao fato que estas foram expostas a alta quantidade de energia, de forma que maior volume se fundiu. Porém, é válido destacar que maiores dimensões podem prejudicar a qualidade da solda, favorecendo a ocorrência de defeitos. Observa-se que, para os aportes de 0,5 kJ/mm e 1,5 kJ/mm, o aço AISI 316L apresentou maior largura e menor penetração que o AISI 316, o que é 
explicado pelo fato do AISI 316L possuir maior condutividade térmica, o que favorece com que a energia adicionada seja difundida pela superfície, porém prejudica a profundidade de penetração da solda. O AISI 316L apresentou maior área que o AISI 316 , exceto para o aporte de $2,5 \mathrm{~kJ} / \mathrm{mm}$. Neste aporte, as amostras foram expostas a maior temperatura, o que fez com que o calor específico do AISI 316L se tornasse maior do que o do AISI 316 (vide Tabela 2), ou seja, para este aporte, foi necessária maior quantidade de calor para aquecer o AISI 316L, acarretando em uma menor poça de fusão.

Tabela 4. Medidas de largura, profundidade de penetração e área do MS de cada amostra soldada.

\begin{tabular}{|c|c|c|c|}
\hline Amostra & Largura (mm) & Penetração (mm) & Área $\left(\mathrm{mm}^{2}\right)$ \\
\hline 5 & 8,51 & 2,86 & 13,33 \\
\hline 15 & 9,05 & 2,96 & 14,93 \\
\hline 25 & 15,26 & 4,22 & 36,22 \\
\hline $5 \mathrm{~L}$ & 12,21 & 2,21 & 16,46 \\
\hline $15 \mathrm{~L}$ & 12,71 & 2,49 & 18,64 \\
\hline $25 \mathrm{~L}$ & 14,44 & 3,00 & 29,20 \\
\hline
\end{tabular}

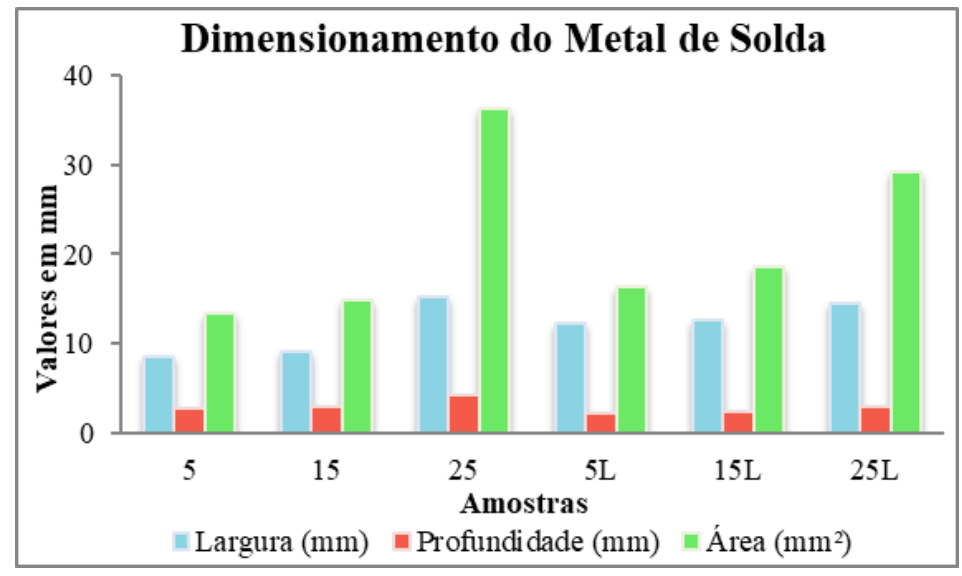

Figura 6. Gráfico comparativo das dimensões dos metais de solda das amostras de AISI 316 e AISI 316L.

\subsection{Análise por MO das amostras soldadas}

As Figuras 7-12 mostram a microestrutura da ZF e da zona de ligação entre ZTA e ZF de cada amostra soldada. É possível visualizar que as ZF's consistem em austenita na forma de dendritas (grãos colunares) com ferrita $\delta$ em rede ou vermicular presente, em maior parte, entre os contornos da austenita. Visualmente, pode-se observar que maiores aportes implicam em maiores dendritas de austenita, pois quando o aporte é maior, o material permanece por mais tempo acima da temperatura líquidus tendo, por consequência, um resfriamento mais lento, havendo mais tempo para os grãos de austenita crescerem e se unirem. Nota-se que a região correspondente a ZTA possui menor alteração microestrutural que a região da ZF. A ZF é uma região que sofre fusão e solidificação, enquanto ZTA é uma região que não sofre fusão, já que atinge menor temperatura durante o processo de soldagem e fica exposta a esta por menor tempo, o que causa menor alteração microestrutural.
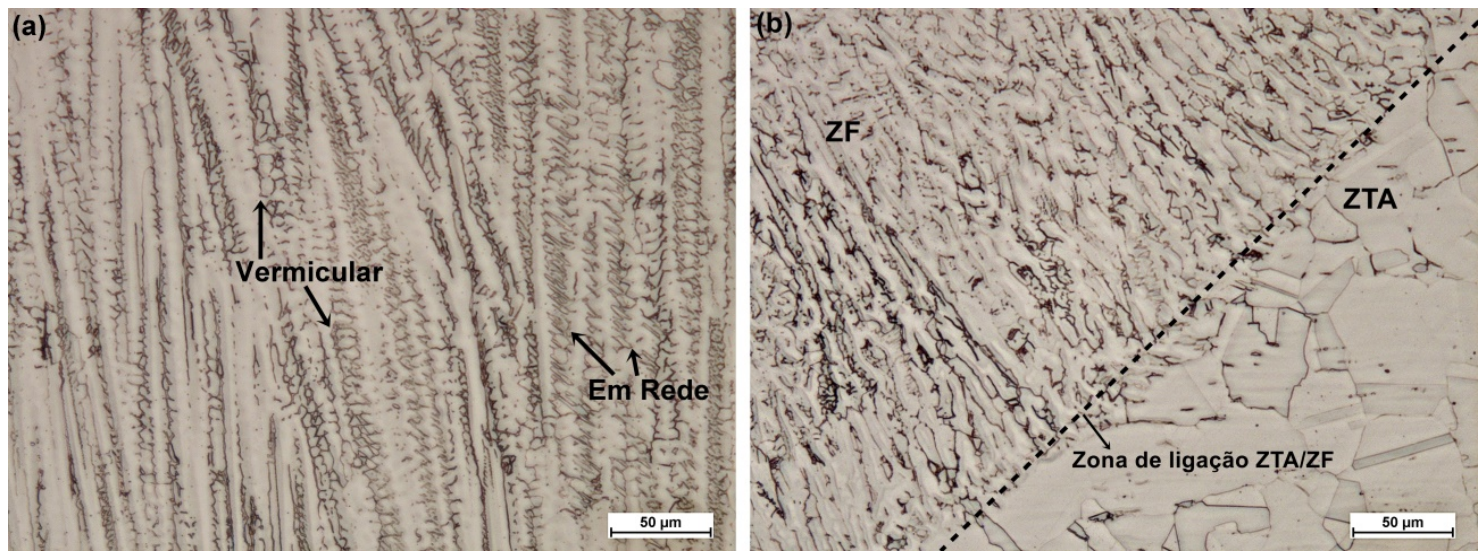

Figura 7. Amostra 5: (a) ZF, (b) Ligação ZF/ZTA. Ataque: Água Régia. Aumento: 200X. 

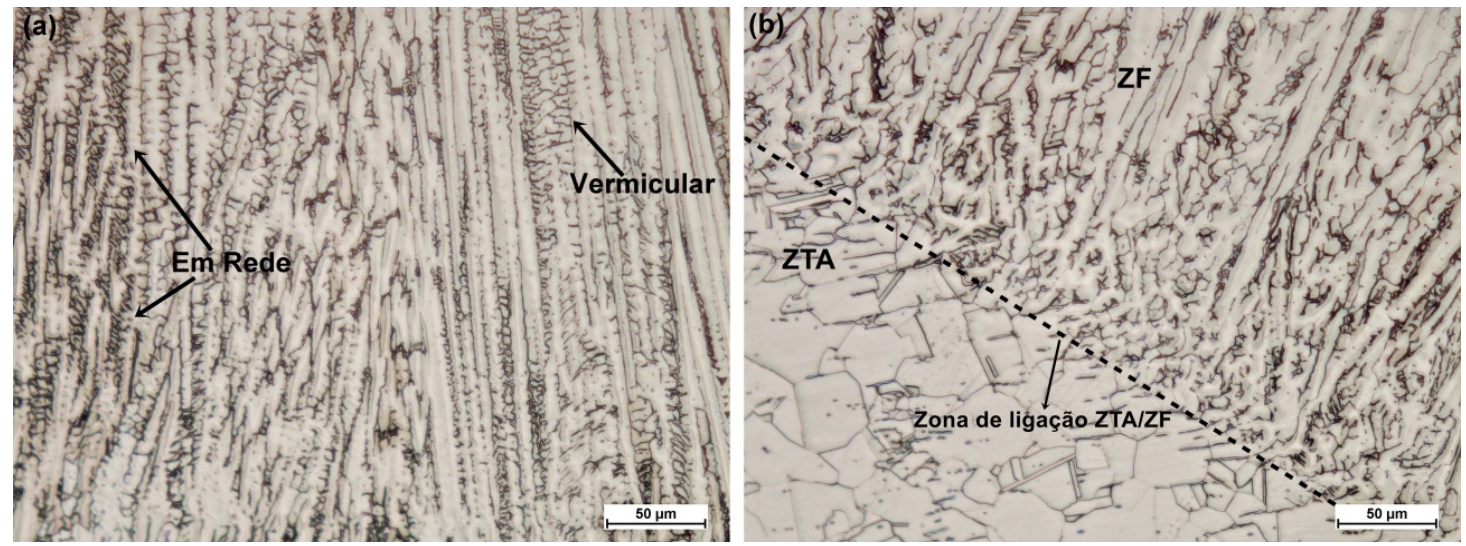

Figura 8. Amostra 15: (a) ZF, (b) Ligação ZF/ZTA. Ataque: Água Régia. Aumento: 200X.
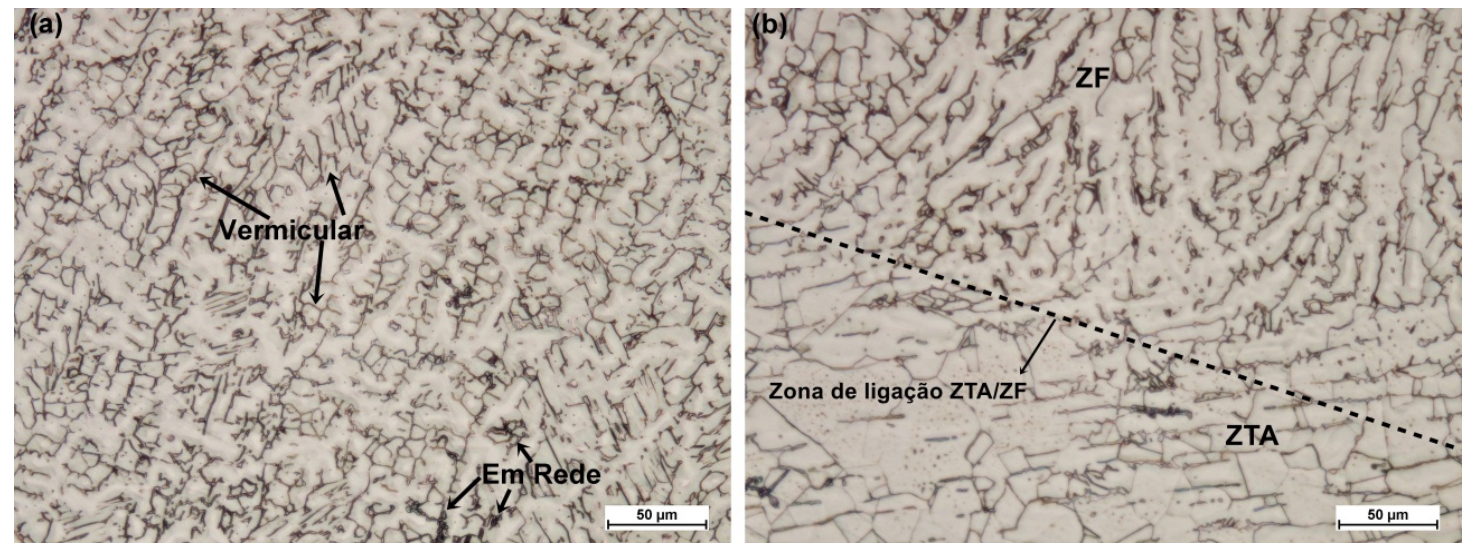

Figura 9. Amostra 25: (a) ZF, (b) Ligação ZF/ZTA. Ataque: Água Régia. Aumento: 200X.
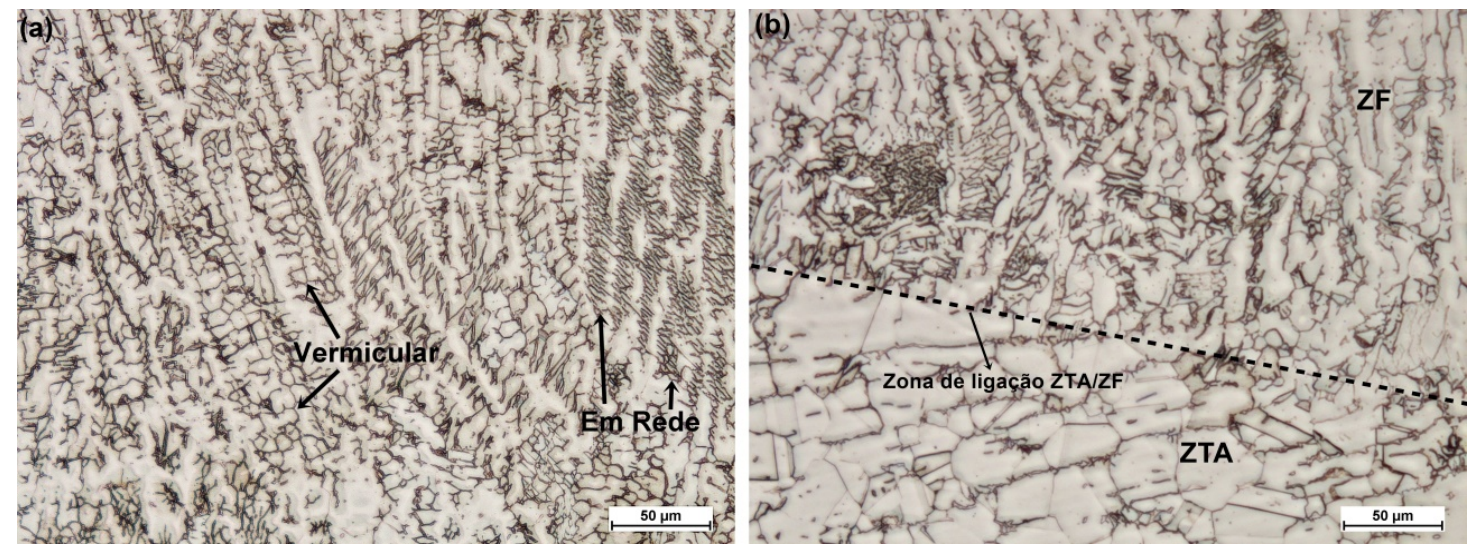

Figura 10. Amostra 5L: (a) ZF, (b) Ligação ZF/ZTA. Ataque: Água Régia. Aumento: 200X. 

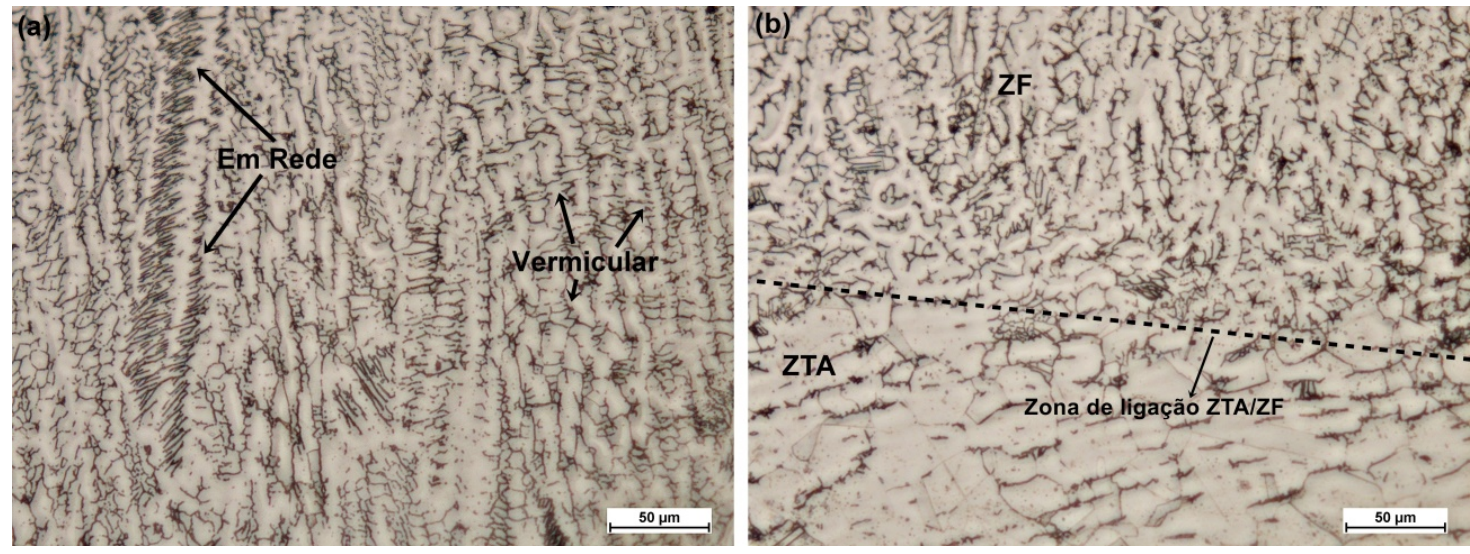

Figura 11. Amostra 15L: (a) ZF, (b) Ligação ZF/ZTA. Ataque: Água Régia. Aumento: 200X.
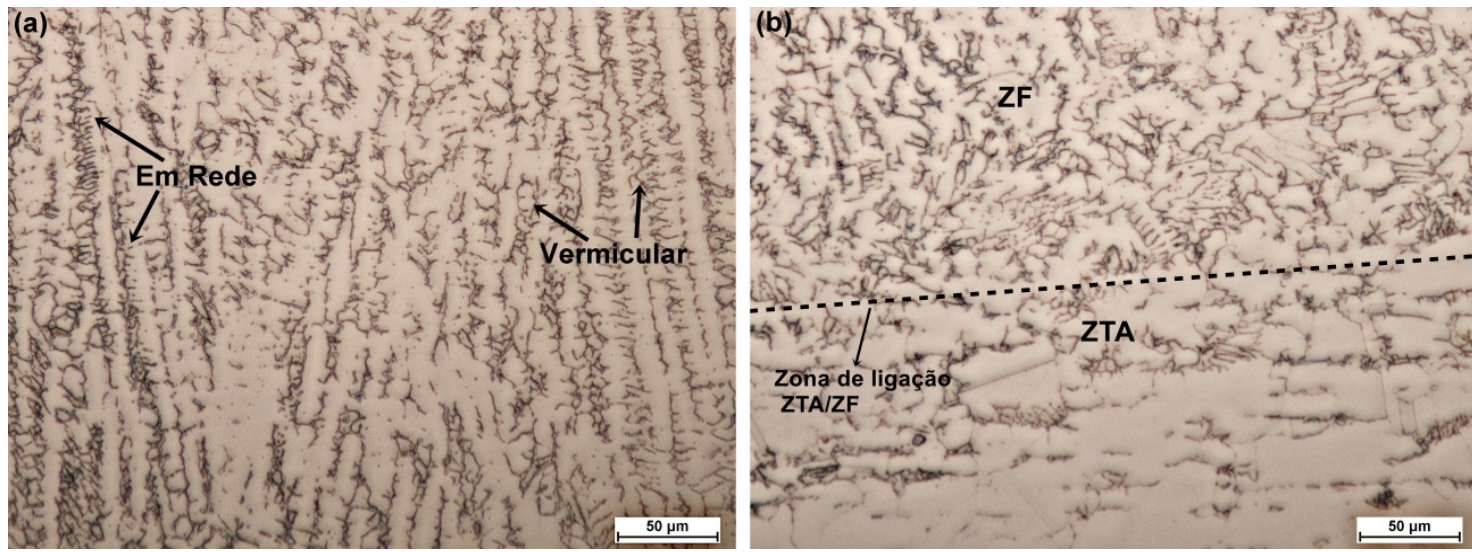

Figura 12. Amostra 25L: (a) ZF, (b) Ligação ZF/ZTA. Ataque: Água Régia. Aumento: 200X.

\subsection{Quantificação e espaçamento entre ferritas $\delta$}

A Tabela 5 mostra os resultados obtidos para a quantificação de ferrita $\delta$ das amostras soldadas com intervalo de confiança de $95 \%$. A fração volumétrica de ferrita $\delta$ torna-se maior com o aumento do aporte, como também observado no estudo de Santos [9], sendo que o aço AISI 316L apresenta maior fração de ferrita, o que se explica devido ao seu menor teor de elementos de liga austenitizantes, como $\mathrm{C}, \mathrm{Ni}, \mathrm{Mn}$ e $\mathrm{N}$.

Tabela 5. Quantificação de ferrita $\delta$ das amostras soldadas.

\begin{tabular}{ccccccc}
\hline Amostra & $\mathbf{5}$ & $\mathbf{1 5}$ & $\mathbf{2 5}$ & $\mathbf{5 L}$ & $\mathbf{1 5 L}$ & $\mathbf{2 5 L}$ \\
Ferrita $(\%)$ & $(16,00 \pm 0,44)$ & $(19,93 \pm 0,51)$ & $(21,23 \pm 0,57)$ & $(18,19 \pm 0,55)$ & $(20,94 \pm 0,67)$ & $(22,79 \pm 0,66)$ \\
\hline
\end{tabular}

As medidas de espaçamento médio entre as ferritas $\delta$ com intervalo de confiança de $95 \%$ se encontram na Tabela 6 . Percebe-se que maiores aportes dão origem a maior espaçamento entre as ferritas $\delta$. Isso ocorre por que, de acordo com Kou [18], maiores aportes implicam em menores taxas de resfriamento. Portanto, durante a solidificação, as dendritas de austenita terão mais tempo para crescer, consequentemente, aumentando o espaçamento entre as ferritas $\delta$, que se encontram em maior parte nos contornos da austenita. A Figura 13 mostra os gráficos comparativos dos resultados da fração de ferrita $\delta$ e espaçamento entre as ferritas.

Tabela 6. Medidas de espaçamento entre ferritas $\delta$.

\begin{tabular}{ccccccc}
\hline Amostra & $\mathbf{5}$ & $\mathbf{1 5}$ & $\mathbf{2 5}$ & $\mathbf{5 L}$ & $\mathbf{1 5 L}$ & $\mathbf{2 5 \mathrm { L }}$ \\
Distância $(\mu \mathrm{m})$ & $(6,51 \pm 0,22)$ & $(7,99 \pm 0,27)$ & $(9,84 \pm 0,28)$ & $(7,08 \pm 0,22)$ & $(9,05 \pm 0,24)$ & $(10,10 \pm 0,19)$ \\
\hline
\end{tabular}


Fração de ferrita $\delta$ para cada aporte

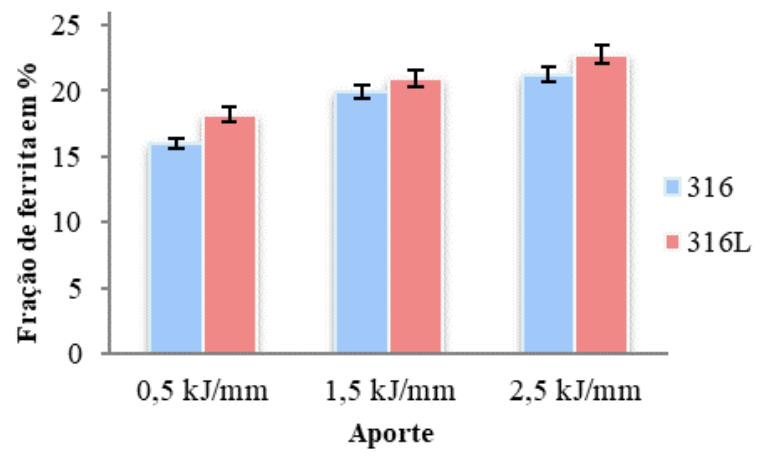

Espaçamento entre ferritas $\delta$

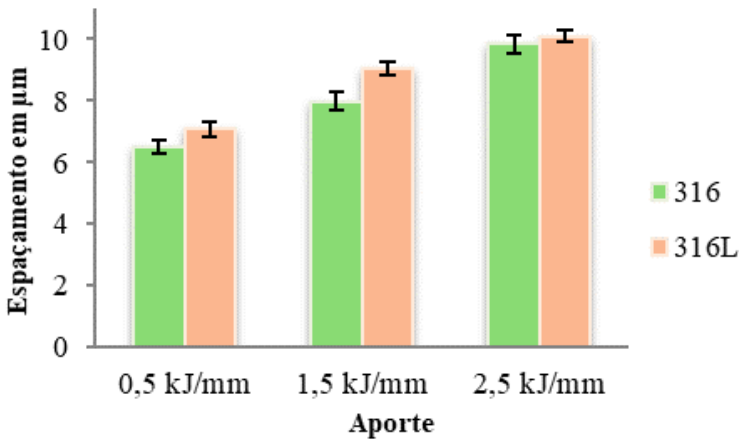

Figura 13. Gráficos comparativos dos resultados da fração de ferrita $\delta$ e espaçamento entre as ferritas.

\subsection{Ensaio de microdureza Vickers}

Os resultados de microdureza das amostras soldadas estão representados nos gráficos comparativos da Figura 14. Como esperado, os valores de microdureza aumentam quando atingem a região da ZF, se tornando maiores quando se aproximam do centro. Isso ocorre devido a ZF possuir maior quantidade de ferrita $\delta$, que é uma fase que possui maior dureza que a austenita. É válido destacar que o ensaio de microdureza é feito em escala micrométrica. Sendo assim, como observado no estudo realizado por Pessanha [19], durante o ensaio, o indentador pode atingir regiões somente de austenita e também regiões com presença parcial de ferrita, o que explica as pequenas variações na microdureza da ZF.
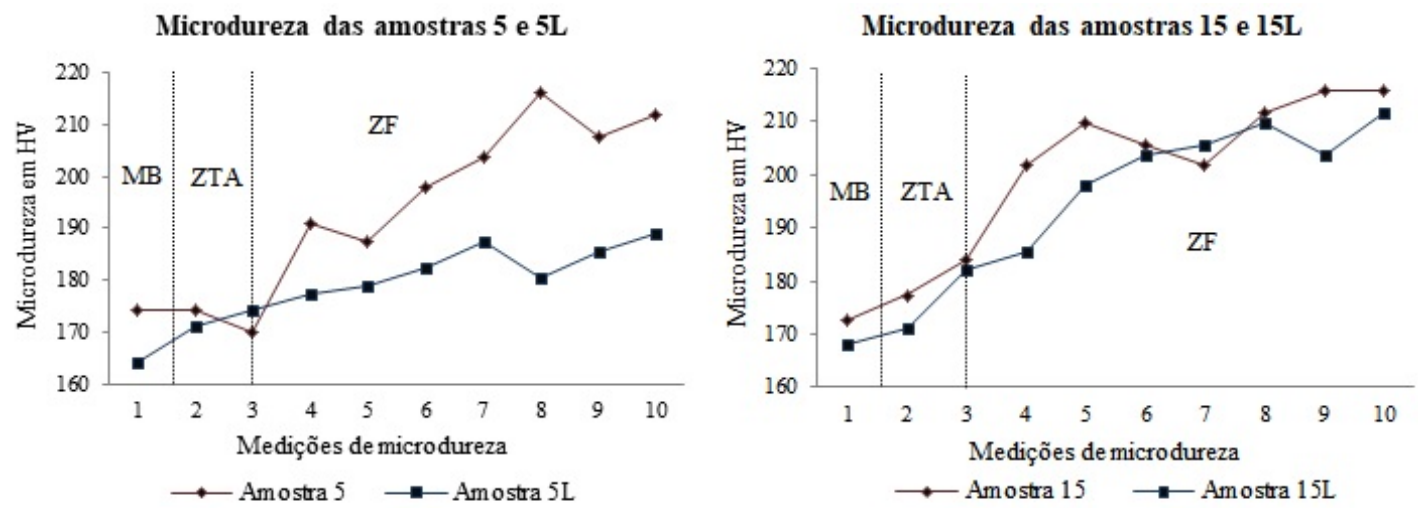

Microdureza das amostras 25 e $25 \mathrm{~L}$

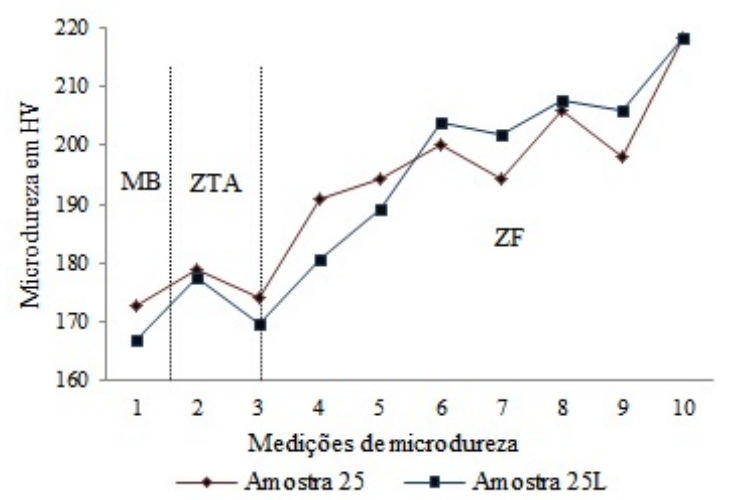

Figura 14. Gráficos comparativos dos resultados de microdureza.

\subsection{Ciclos térmicos e distribuição de temperatura por modelagem computacional}

A Figura 15 mostra os ciclos térmicos dos aços AISI 316 e AISI 316L obtidos pelo modelo numérico em comparação com os ciclos medidos experimentalmente para o aporte de $0,5 \mathrm{~kJ} / \mathrm{mm}$. Observa-se que as curvas calculadas para ambos os aços se encontram próximas aos seus respectivos resultados medidos experimentalmente, o que indica boa confiabilidade dos resultados obtidos por simulação. 


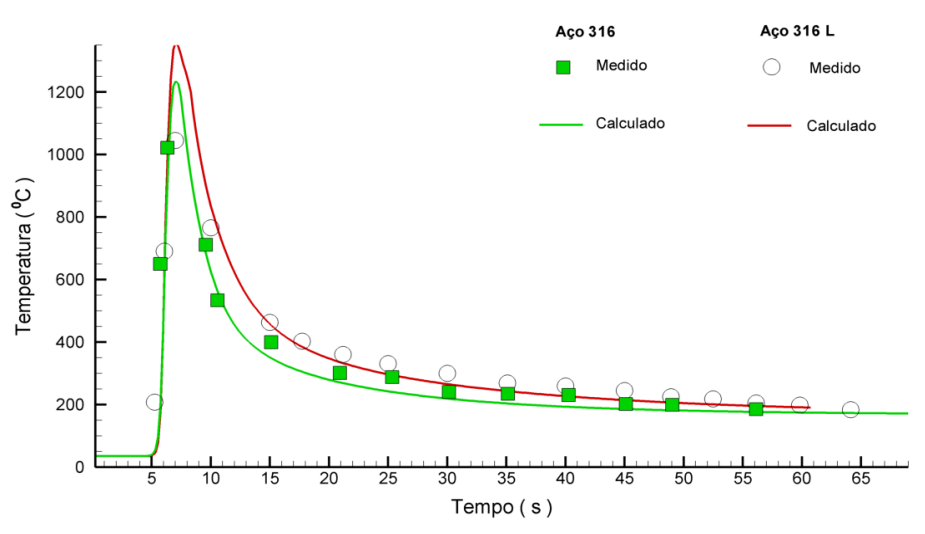

Figura 15. Ciclos térmicos dos aços AISI 316 e AISI $316 \mathrm{~L}$ soldados com aporte de $0,5 \mathrm{~kJ} / \mathrm{mm}$.

A Figura 16 apresenta a distribuição de temperatura durante o processo de soldagem calculada pelo modelo numérico para o aporte térmico de $0,5 \mathrm{~kJ} / \mathrm{mm}$ em dois instantes de tempo. A região vermelha na chapa, região de maior temperatura, indica a localização da tocha de soldagem no instante indicado do processo. Logo, as cores quentes (vermelho, laranja e amarelo) indicam a região onde ocorreu a fusão do material. A região azul ciano (temperatura em torno de 400 a $600{ }^{\circ} \mathrm{C}$ ) corresponde a ZTA, enquanto a região verde representa a transição entre ZF e a ZTA. As regiões em azul escuro correspondem ao metal base.

(a)

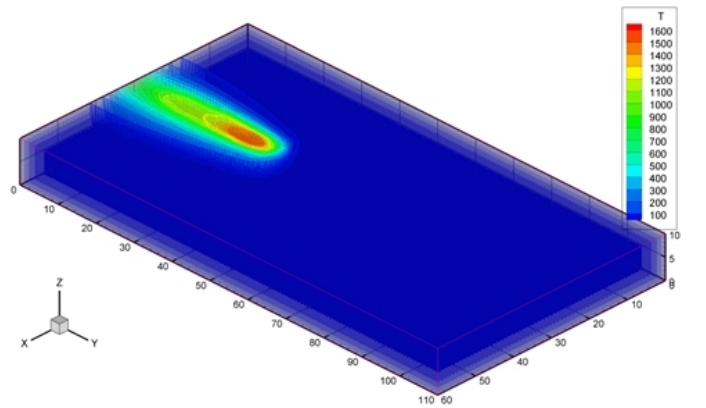

(b)

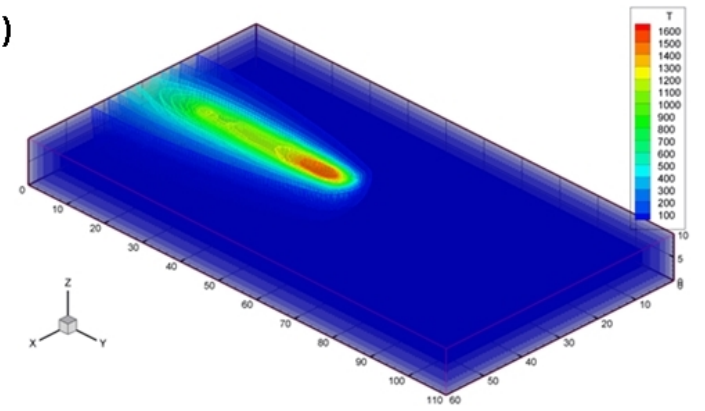

Figura 16. Distribuição de temperatura durante a soldagem com o aporte de $0,5 \mathrm{~kJ} / \mathrm{mm}$ aos (a) 4,5 segundos e (b) 6,5 segundos.

As Figuras 17-19 mostram os ciclos térmicos calculados para três termopares localizados em regiões distintas das chapas de AISI 316 e AISI 316L, como mostra a Figura 2, para os aportes de 0,5 kJ/mm, 1,5 kJ/mm e 2,5 kJ/mm, respectivamente. A Figura 20 evidencia, através dos resultados do modelo numérico, que quanto maior o aporte, maior a temperatura de pico. Além disso, temperaturas de pico mais altas resultam em menores taxas de resfriamento, ou seja, maior tempo de resfriamento. O aço AISI $316 \mathrm{~L}$ soldado com aporte de $2,5 \mathrm{~kJ} / \mathrm{mm}$, por exemplo, foi o ensaio que atingiu maior temperatura de pico, apresentando uma taxa de resfriamento menor quando comparado aos demais ensaios de ambas as amostras. Pode-se observar que o aço AISI 316L atingiu maiores temperaturas de pico comparado aos mesmos aportes do AISI 316, o que pode ser explicado pelas propriedades físico-químicas apresentadas pelo aço AISI 316L. Apesar de atingir maiores temperaturas, o $316 \mathrm{~L}$ apresenta menor profundidade de penetração medida experimentalmente, como mostra a Tabela 4, o que pode ser explicado pela maior condutividade térmica deste aço, propriedade que prejudica a penetração da solda. 


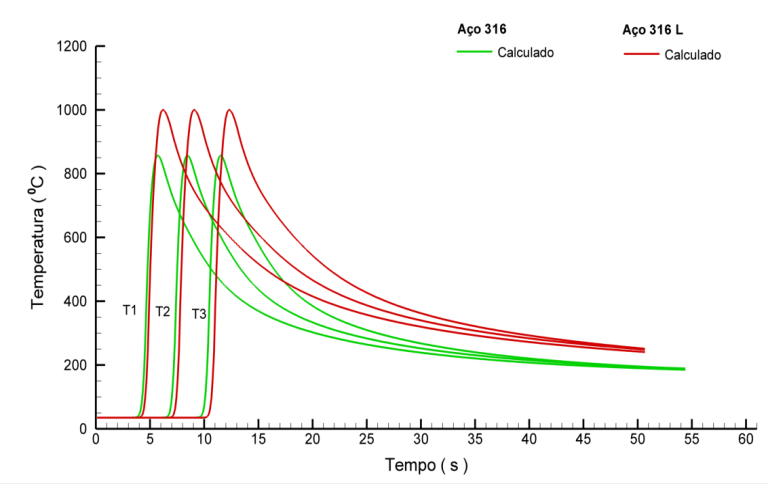

Figura 17. Ciclo térmico calculado pelo modelo em três pontos distintos, aporte $0,5 \mathrm{~kJ} / \mathrm{mm}$.

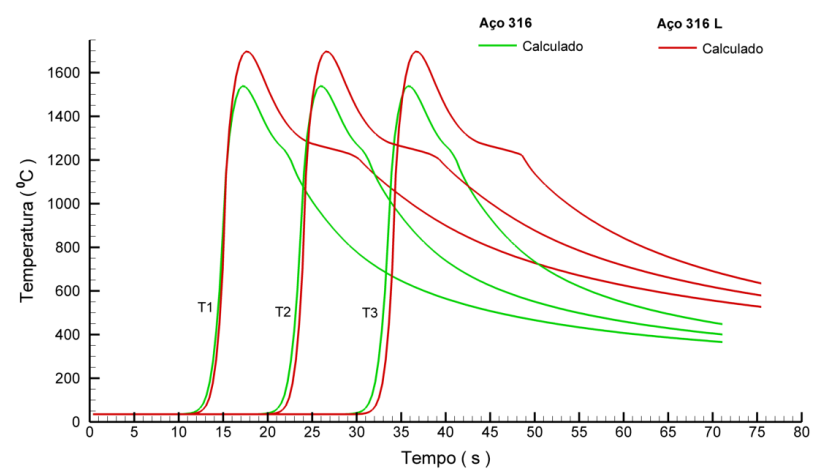

Figura 18. Ciclo térmico calculado pelo modelo em três pontos distintos, aporte $1,5 \mathrm{~kJ} / \mathrm{mm}$.

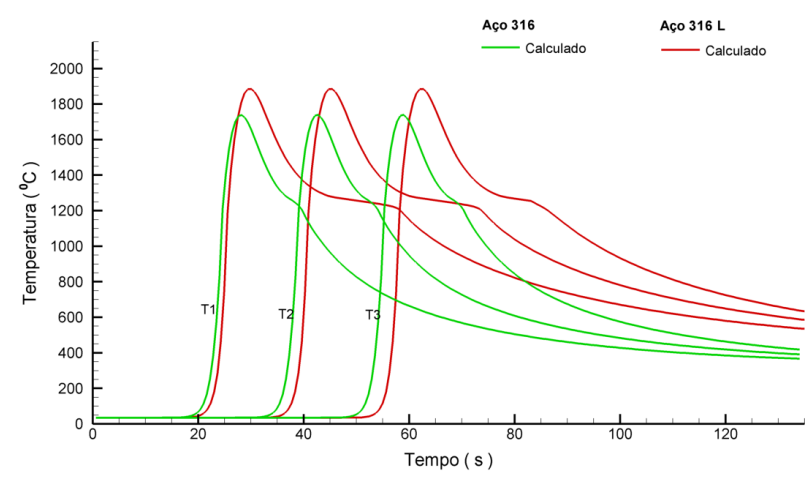

Figura 19. Ciclo térmico calculado pelo modelo em três pontos distintos, aporte $2,5 \mathrm{~kJ} / \mathrm{mm}$.
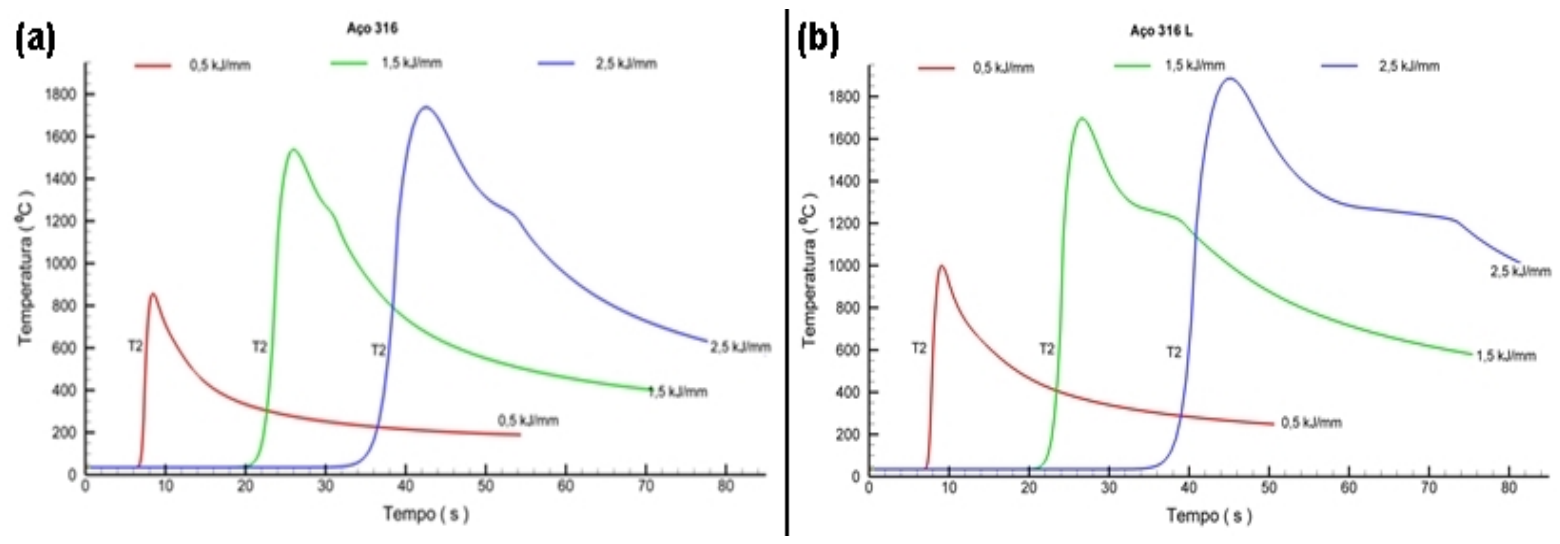

Figura 20. Ciclos térmicos calculados para os três aportes da (a) amostra AISI 316 e (b) amostra AISI 316L. 


\section{Conclusão}

O presente estudo apresentou uma análise comparativa bem sucedida da soldabilidade de dois aços inoxidáveis muito utilizados no setor industrial, o AISI 316 e AISI 316L. Seguem as principais conclusões:

- $\quad$ a aumento do aporte térmico de soldagem de ambos os aços acarretou no aumento do espaçamento entre bandas de ferrita $\delta$, da fração volumétrica de ferrita $\delta$ e do aumento nas dimensões do metal de solda.

- As amostras 5L e 15L apresentaram área do metal de solda aproximadamente 20\% maior que a área das amostras 5 e 15 , respectivamente, enquanto a amostra $25 \mathrm{~L}$ apresentou área $19 \%$ menor que a amostra 25 , como explicado no item 3.2 .

- $\quad$ aço AISI 316L apresentou maior fração volumétrica de ferrita $\delta$ e maior espaçamento entre bandas de ferrita que o aço AISI 316, o que pode ser explicado pelo fato do 316L apresentar menor teor de elementos austenitizantes.

- O ciclo térmico de soldagem obtido por simulação para o aporte de $0,5 \mathrm{~kJ} / \mathrm{mm}$ se encontra próximo ao ciclo térmico obtido experimentalmente, indicando boa confiabilidade do modelo utilizado para o menor aporte.

- $\quad O$ aporte de $2,5 \mathrm{~kJ} / \mathrm{mm}$ apresentou maior fração de ferrita $\delta$ e maiores dimensões do metal de solda, características que podem prejudicar a obtenção de uma solda de qualidade, como explicado nos itens 3.2 e 3.4. Assim, os aportes mais indicados para o processo de soldagem são os aportes de $0,5 \mathrm{~kJ} / \mathrm{mm}$ e $1,5 \mathrm{~kJ} / \mathrm{mm}$. A escolha entre um destes dependerá da espessura da amostra. Sendo que, para espessuras mais finas, recomenda-se o aporte de 0,5 kJ/mm, já que maiores aportes podem acarretar em defeitos.

\section{Agradecimentos}

O presente trabalho foi realizado com apoio da Coordenação de Aperfeiçoamento de Pessoal de Nível Superior - Brasil (CAPES) - Código de Financiamento 001, 2019.

\section{Referências}

[1] Mcguire MF. Stainless steels for design engineers. Materials Park, OH: ASM International; 2008. $304 \mathrm{p.}$ http://dx.doi.org/10.31399/asm.tb.ssde.9781627082860.

[2] Costanza G, Sili A, Tata ME. Weldability of austenitic stainless steel by metal arc welding with different shielding gas, 21st European Conference on Fracture. Procedia Structural Integrity. 2016;2:3508-3514. http://dx.doi.org/10.1016/j.prostr.2016.06.437.

[3] Balram Y, Vishu Vardhan T, Sridhar Babu B, Venkat Ramana G, Preethi C. Thermal stress analysis of AISI 316 stainless steels weldments in TIG and pulse TIG welding processes. Materials Today: Proceedings. 2019;19(2):182-187. http://dx.doi.org/10.1016/j.matpr.2019.06.695.

[4] Samanta SK, Mitra SK, Pal TK. Effect of rare earth elements on microstructure and oxidation behaviour in TIG weldments of AISI 316L stainless steel. Materials Science and Engineering A. 2006;430(1),242-247.

[5] Almeida DF, Martins RF, Cardoso JB. Numerical simulation of residual stresses induced by TIG butt-welding of thin plates made of AISI 316L stainless steel. Procedia Structural Integrity. 2017;5:633-639. http://dx.doi.org/10.1016/j.prostr.2017.07.032.

[6] Goldak J, Chakravarti A, Bibby M. A new finite element model for welding heat sources. Metallurgical Transactions B. 1984;15(2):299305.

[7] Xavier CR. Simulação numérica da soldabilidade dos aços ferríticos T/P23 e T/P24 [dissertação de mestrado]. Porto Alegre: Universidade Federal do Rio Grande do Sul; 2009. 72 p.

[8] Ronda J, Oliver GJ. Consistent thermo-mechano-metallurgical model of welded stell with unified approach to derivation of phase evolution laws and transformation-induced plasticity. Computer Methods in Applied Mechanics and Engineering. 2000;189(2):361-418. http://dx.doi.org/10.1016/S0045-7825(99)00461-2.

[9] Santos EP. Estudo comparativo das transformações microestruturais e termometalurgicas de juntas soldadas dos aços inoxidáveis AISI 316 e AISI 316L pelo processo TIG autógeno [dissertação de mestrado]. Volta Redonda: Universidade Federal Fluminense; 2017.100 p.

[10] Modenesi PJ, Marques PV, Santos DB. Introdução à metalurgia da soldagem. Belo Horizonte: Universidade Federal de Minas Gerais; 2012. 209 p.

[11] American Society for Testing and Materials. ASTM E112-12: Standard test methods for determining average grain size. West Conshohocken: ASTM; 2012. 27 p.

[12] Goldak JA, Akhlaghi M. Computatiol welding mechanics. 1. ed. New York: Springer; 2005. 322 p.

[13] Patankar SV. Numerical heat transfer and fluid flow. 1. ed. Oxfordshire, UK: Taylor\&Francis; 1980. 197 p.

[14] Tavares SSM, Souza VM, Souza JA, Kina AY. Influência dos tratamentos térmicos de estabilização e solubilização na resistência à corrosão intergranular do aço inoxidável AISI 347 fundido. Tecnologia em Metalurgia e Materiais. 2008;4(3):18-22. http://dx.doi.org/10.4322/tmm.00403004. 
[15] Demarque R, Silva RS, Santos EP, Castro JA. Avaliação de parâmetros de soldagem nas características de juntas dissimilares Inconel 718 inox 316L soldadas pelo processo TIG autógeno. Soldagem e Inspeção. 2018;23(3):380-392. http://dx.doi.org/10.1590/01049224/si2303.07.

[16] Souza LH, Xavier CR, Medeiros N, Marcelo CJ, Moreira LP. Avaliação da soldagem TIG autógena sobre as características dimensionais da solda do aço AISI 304L. In: Associação Brasileira de Engenharia e Ciências Mecânicas. Anais do 9th Congresso Nacional de Engenharia Mecânica; 2016 Agosto 21-25; Fortaleza. Rio de Janeiro: ABCM; 2016.

[17] Royse, FS. Estudo das propriedades mecânicas e microestruturais de revestimento de liga de cobalto utilizando o processo de soldagem TIG [dissertação de mestrado] Rio de Janeiro: CEFET; 2011. 129 p.

[18] Kou S. Welding metallurgy. 2. ed. New York: John Wiley \& Sons, 2003. 461 p.

[19] Pessanha EC. Quantificação da ferrita delta e avaliação da relação microestrutura/propriedades de um aço inoxidável austenítico 347 soldado [dissertação de mestrado]. Campos dos Goytacazes: Universidade Estadual do Norte Fluminense; 2011. 95 p. 